\title{
Early Outcomes Following off-Pump Coronary Artery Bypass Surgery under General Anaesthesia with and without High Thoracic Epidural Analgesia: A Comparative Study
}

\author{
Monalisa Datta, Chaitali Sen Dasgupta*, Anupam Goswami, \\ Department of Cardiac Anaesthesiology, Institute of Post Graduate Medical Education and Research, Kolkata
}

*Corresponding Author: Chaitali Sen Dasgupta, Department of Cardiac Anaesthesiology, Institute of Post Graduate Medical Education and Research, Kolkata

Received Date: June 24, 2021; Accepted Date: July 05, 2021; Published Date: July 09, 2021

Citation: Monalisa Datta, Chaitali SenDasgupta, Anupam Goswami (2021) Early Outcomes Following off-Pump Coronary Artery Bypass Surgery under General Anaesthesia with and without High Thoracic Epidural Analgesia: A Comparative Study. J. Clinical Cardiology and Cardiovascular Interventions, 4(13); Doi:10.31579/2641-0419/198

Copyright: (C) 2021 Chaitali Sen Dasgupta, This is an open-access article distributed under the terms of the Creative Commons Attribution License, which permits unrestricted use, distribution, and reproduction in any medium, provided the original author and source are credited.

\begin{abstract} coronary artery bypass (OPCAB) surgery. VAS score is $>40$ in the postoperative period.

Keywords: Epidural; OPCAB; ropivacaine; fentanyl

Running Title: Epidural GA OPCAB

Reduction of postoperative morbidity by providing optimal pain relief and improving quality of care is an important goal of current anaesthesia practice. The search for improvements of quality of recovery for patients undergoing off-pump coronary artery bypass (OPCAB) surgery is an important target for cardiac anaesthesiologists. Supplementation of regional with general anaesthesia, in both adult and pediatric patients undergoing major surgery is receiving increasing attention from
\end{abstract}

Introduction: Reduction of postoperative morbidity by providing optimal pain relief and improving overall quality of care is an important goal of modern anaesthesia practice. The aim of this prospective, randomized, open, controlled study is to investigate the impact of high thoracic epidural analgesia on early clinical outcomes in patients undergoing off-pump

Methodology: After obtaining the institutional ethics committee approval and written informed consent from all patients, 80 patients of either sex, aged 40 - 70 years, scheduled for elective primary OPCAB surgery were randomized into two groups. Group I received $4 \mathrm{~mL}$ of an epidural bolus of $1 \%$ ropivacaine and fentanyl $100 \mu \mathrm{g}$ followed by ropivacaine $1 \%$ and fentanyl $5 \mu \mathrm{g} / \mathrm{mL}$ infusion for $72 \mathrm{~h}$ at $3-5 \mathrm{~mL} / \mathrm{h}$ postoperatively. Analgesia in the Group II was provided with a continuous IV fentanyl infusion. Patients were given rescue analgesic (inj Tramadol intravenous) when

Results: VAS score, need for rescue analgesics and incidence of postoperative arrythmia were significantly lower in Group I specially for first twenty four hours postoperatively. Time for extubation and length of postoperative ICU stay were found similar in both the groups. Incidence of other outcomes found to be not significant.

Conclusion: The pain scores, analgesic requirements and incidence perioperative arryrhmias were significantly less in Group I compared to Group II, but we could not be able to find any significant difference in time for extubation and length of ICU stay, neither in incidence of postoperative MI, CVA, renal failure, blood transfusion and death.

\section{Introduction:} anaesthetiologists and cardiac surgeons. [1-6]
High thoracic epidural anaesthesia (TEA) during cardiac surgery promotes sympatholysis and attenuates the stress response of surgery. $[1,2]$ TEA may also enhance coronary perfusion, [3] improves myocardial oxygen supply and reduce the incidence of tachyarrhythmias.[1] Through the same mechanism, the incidence of perioperative myocardial infarction could be reduced. [4] Moreover, the excellent analgesia associated with TEA facilitates early tracheal extubation and may prevent respiratory complications. [5-7]

Along with these potential benefits of TEA, however, there is a risk for potential harm caused by an epidural hematoma that may develop after an 
epidural puncture and catheter insertion, especially in patients who need full heparinization for cardiopulmonary bypass. [8]

Although epidural haematoma has been reported, the frequency is not more when compared to its use in noncardiac surgery, with the latest published risk estimate being 1:12,000. [9]

The aim of this prospective, randomized, open, controlled study is to compare the effect of high thoracic epidural analgesia with that of conventional general anaesthesia (GA) on early postoperative outcomes in patients undergoing off-pump coronary artery bypass (OPCAB) surgery.

\section{Material and method:}

This prospective, randomized, open study was carried out from March 2012 to December 2013.

\section{Inclusion Criteria:}

After obtaining the institutional ethics committee approval and written informed consent from each patients, 50 patients of either sex, aged $40-$ 70 years, with a normal coagulation screen and an ejection fraction of $>0.35$ with modified Personnet score $<10$, scheduled for elective OPCAB were included in this study.

\section{Exclusion Criteria:-}

1. Patients with Modified Personnet score $>10$

2. Patients having associated heart valve pathology.

3. Patients having significant left main coronary artery disease (LMCA).

4. History of bleeding disorder, abnormal coagulation profile or patients on anticoagulant/antiplatelet therapy like intravenous heparin, warfarin or clopidogrel at the time of surgery,

5. Patients with any absolute or relative contraindication to epidural anaesthesia.

6. Existing renal, metabolic, neurological and psychiatric disorders.

\section{Preanaesthetic check-up:-}

During preanaesthetic visit, patients were given all the relevant information about the procedure, advantages and complications of epidural analgesia specially regarding epidural hematoma formation and it consequences, and written informed consents were obtained from each patient. A thorough clinical examination including neurological examination for deep tendon reflexes, muscle tone, and power in the limbs was done and pulse rate, blood pressure, respiratory rate, other co-morbid conditions were recorded. All investigations were also finally checked at that time.

Angiotensin-converting enzyme inhibitors were advised to suspend a day before surgery, calcium-channel antagonists and $\beta$-adrenergic blocking drugs continued until the morning of surgery. $\beta$-blockers was not used intraoperatively or postoperatively during the study period in any patient.

Premedication in both groups consisted of alprazolam $0.25 \mathrm{mg}$ on night before surgery; tab ranitidine $150 \mathrm{mg}$, and metclopropramide $10 \mathrm{mg}$, orally, the night before surgery and was repeated on morning, two hours before surgery.

\section{Randomization:-}

On the morning of surgery, patients were randomized to one of two groups by sealed envelope technique performed by an independent member staff by using cards drawn from a sealed envelope. Group I patients received GA plus perioperative thoracic epidural analgesia and Group II received GA plus perioperative opioid analgesia.

\section{Anaesthesia proper:-}

Patients were wheeled into operation theatre and standard ASA monitors (pulse oxymeter, NIBP till the IBP were done, 5 lead ECG) were attached. An intravenous line was inserted in all patient in right dorsum or forearm. In patients in Group I a thoracic epidural catheter was inserted via an 18gauge Tuohy needle at the T2-3 or T3-4 interspace, under total aseptic precaution, through midline approach, at least one hour before incision. The location of the catheter was then verified with a test dose of $3 \mathrm{ml}$ of lidocaine $2 \%$. In case of a "bloody tap", it was decided to postpone the surgery for $24 \mathrm{~h}$ or till the neurologic examination was completely normal.

Bilateral neuraxial block upto T1 to T10 segments was established with epidural bolus of $4 \mathrm{ml}$ of $1 \%$ ropivacaine and fentanyl $100 \mu \mathrm{g}$ and height of block was determined with ethyl alcohol swab before induction of GA. If the block was doubtful, then supplemental dose of $6 \mathrm{ml} 1 \%$ ropivacaine was given. Failure to obtain a block with $10 \mathrm{ml}$ of $1 \%$ ropivacaine was considered malposition of the epidural catheter; alternative method of analgesia was implemented in those cases, and the patient was excluded from analysis.

Arterial cannulation was done in all patients in left radial artery under local anaesthesia and invasive blood pressures monitoring was commenced.

Induction of anaesthesia was done with inj midazolam $(0.03 \mathrm{mg} / \mathrm{kg})$, fentanyl $(5 \mu \mathrm{g} / \mathrm{kg})$ and thiopentone $(2-3 \mathrm{mg} / \mathrm{kg})$ till eyelash reflex was lost. Neuromuscular blockade was achieved by $0.9 \mathrm{mg} / \mathrm{kg}$ rocuronium, and following endotracheal intubation, the lungs were ventilated with nitrous oxide in oxygen $(45-50 \%)$. End-tidal carbon dioxide was maintained between 35 and $40 \mathrm{mmHg}$ throughout. Temperature was maintained at 36 degrees. Central venous cannulation was performed thereafter. After the central venous cannulation, in Group I, an epidural analgesia was commenced with ropivacaine $1 \%$ and fentanyl $5 \mu \mathrm{g} / \mathrm{mL}$ at the rate of $3-$ $5 \mathrm{~mL} / \mathrm{h}$ while patients in Group II received a continuous intravenous fentanyl infusion $(2 \mu \mathrm{g} / \mathrm{kg} / \mathrm{hr})$ as analgesia. Before incision, inj fentanyl, vecuronium and midazolam were repeated and surgery was started. Anaesthesia was maintained with isoflurane $0.8-1.0 \%$ (with $\mathrm{N}_{2} \mathrm{O}$ and $\mathrm{O}_{2}$ at 50: 50 ratio), vecuronium bromide $(0.04 \mathrm{mg} / \mathrm{kg})$, midazolam $(0.02 \mathrm{mg} / \mathrm{kg})$ and fentanyl $(1 \mu \mathrm{g} / \mathrm{kg})$.

All the operations were performed by one specific surgeon with assistants.

All the drugs were repeated as bolus, before sternotomy and every 30 minutes interval. Heparin (100 units/kg) was administered before the start of the first distal anastomosis to achieve an activated clotting time of 150 250s and repeated hourly to maintain ACT between 150-250s.

All anastomosis were performed with standard positioning and with suction stabilizer device (ESTECH 401- 230- OPVAC). Intraoperative monitoring included continuous arterial blood pressure, heart rate, 5 lead electrocardiography with ST segment analysis, pulmonary capillary wedge pressure (PCWP) or central venous pressure (CVP), temperature, urine output, saturation of $\mathrm{O}_{2}\left(\mathrm{SpO}_{2}\right)$, end tidal carbon dioxide level $\left(\mathrm{EtCO}_{2}\right)$ along with arterial blood gas $(\mathrm{ABG})$ analysis after induction (baseline), after sternotomy and after completion of each anastomosis. 
Intraoperative haemodynamic management was similar for both groups and aimed to maintain the MAP between 65 and $85 \mathrm{~mm} \mathrm{Hg}$. Hypotension was treated with IV crystalloid fluids until the PCWP was $>18 \mathrm{~mm} \mathrm{Hg}$ or CVP $>10 \mathrm{~mm} \mathrm{Hg}$. Dopamine $5 \mu \mathrm{g} / \mathrm{kg} / \mathrm{min}$ was started when the SBP was $<90 \mathrm{mmHg}$ persistently and was increased to $10 \mu \mathrm{g} / \mathrm{kg} / \mathrm{min}$ if required. Dopamine was supplemented by adrenaline $0.05 \mu \mathrm{g} / \mathrm{kg} / \mathrm{min}$ in case of persistent hypotension and increased to $1 \mu \mathrm{g} / \mathrm{kg} / \mathrm{min}$ if necessary. Hypertension was treated with IV fentanyl $5 \mu \mathrm{g} / \mathrm{kg}$ bolus in the Group II or with a bolus of epidural ropivacaine $1 \% 2 \mathrm{ml}$ in the Group I. Persistent hypertension was treated with deepening of anaesthesia followed by bolus of propofol $(0.5 \mathrm{mg} / \mathrm{kg})$ up to a maximum of three boluses per hour, with the commencement of a nitroglycerine infusion $(0.5 \mu \mathrm{g} / \mathrm{kg} / \mathrm{min}-1$ $\mu \mathrm{g} / \mathrm{kg} / \mathrm{min}$ ) in both groups.

On completion of all anastomoses, once surgical bleeding was controlled and the patient was hemodynamically stable with acceptable blood gas analysis report, the effect of heparin was reversed with protamine.

\section{Postoperative period:-}

All patients in both groups received intravenous paracetamol $(1 \mathrm{~g})$ every $6 \mathrm{~h}$ as a baseline analgesic.

In the Group I, the epidural infusion was continued for $72 \mathrm{~h}$ at the same rate (ropivacaine $1 \%$ and fentanyl $5 \mu \mathrm{g} / \mathrm{mL}$, at a rate of $3-5 \mathrm{~mL} / \mathrm{h}$.). Analgesia in the Group II was provided with continuous fentanyl infusion at the rate of $2 \mu \mathrm{g} / \mathrm{kg} / \mathrm{hr}$ till $72 \mathrm{hrs}$ postoperatively.

Analgesia was assessed by an anaesthesia resident, who was completely unaware about the nature of the study, with the help of visual analogous pain score (VAS), at rest and with coughing. The VAS was determined after extubation, on first three postoperative days four hourly and twice (8 AM \& 8 PM) daily thereafter until discharge from ICU or until Day 7 whichever was earlier and also whenever necessary if patient complains of severe pain. Patients were given rescue analgesic (inj Tramadol $2 \mathrm{mg} / \mathrm{kg}$ intravenous) when VAS score is $>40$ with coughing. Total requirement of tramadol, fentanyl, morphine, inotropes and vasodilators were recorded.

Incidence of postoperative complications were defined as below and noted during the ICU stay period for each patient. New arrhythmia was recorded if there was any and was treated accordingly. [11] When haematocrit was less than or equal to $23 \%$ postoperatively, blood transfusion was considered. [12] Perioperative myocardial infarction (MI) was defined as new $\mathrm{Q}$ waves of $0.04 \mathrm{~ms}$ and/or a reduction in $\mathrm{R}$ waves more than $25 \%$ in at least two contiguous leads on electrocardiogram [13] Diagnosis of CVA was made if there is evidence of new neurologic deficit with morphological substrate confirmed by computed tomography or magnetic resonance imaging [13] Chest infection, defined as the presence of purulent sputum associated with fever and requiring antibiotic therapy according to positive sputum culture. $\beta$-blocker therapy was started on the fifth post operative day in all patients, except in those patients who developed a new arrhythmia that required additional therapy.

Statistical Analysis:- Statistical Analysis was done using standard statistical software SPSS version 20. Haemodynamic parameters and other normally distributed numerical variables were compared between groups by independent sample student " $t$ " test. Mann-Whitney U test was used for variables which were not normally distributed (by KolmogorovSmirnov goodness-of-fit test). Categorical variables were compared between groups by Fischer's exact test. All analysis was two-tailed and a p-value $<0.05$ was considered as statistically significant.

\section{Results:-}

Baseline demographic and medication parameters were similar between two groups. All patients had undergone an uneventful intraoperative period.

Haemodynamic parameters were recorded continuously and there was no significant difference between the two groups (Figure. 1).

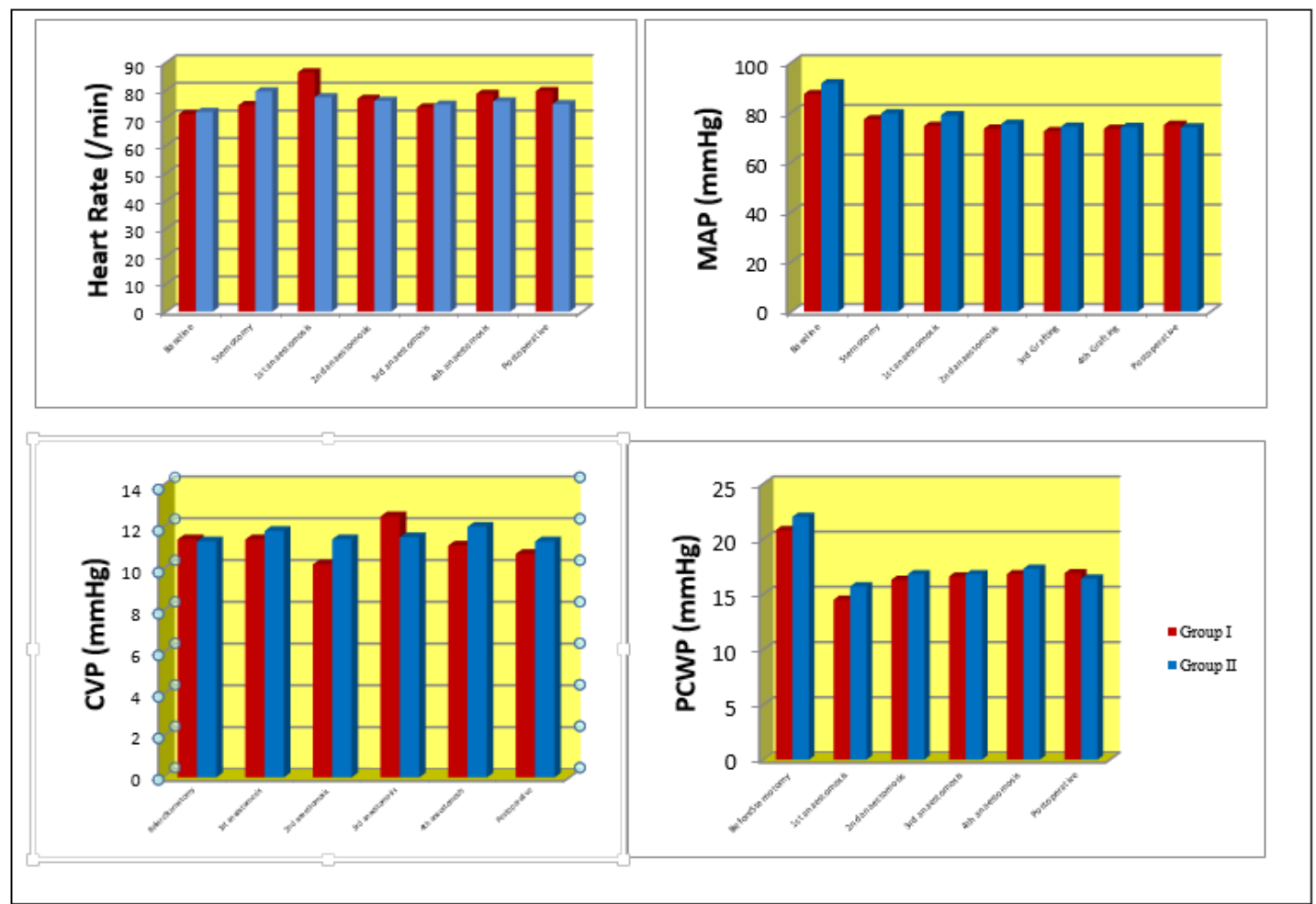

Figure 1: Haemodynamic Parameters (Intraoperative Period) 
Intraoperative arterial blood gas (ABG) parameters $\left(\mathrm{pH}, \mathrm{PaO}_{2} / \mathrm{FiO}_{2}\right.$, $\mathrm{PCO}_{2}$ and $\mathrm{BE}$ ) were also found to be comparable between the two groups, but $\mathrm{PCO}_{2}$ was found to be significantly less in $\mathrm{Gr} \mathrm{I}$ in first postoperative day compared to Gr II $(\mathrm{p}=0.004)$.

The median time of extubation in Group I (Gr I) was $8.68 \pm 34.801$ where as in Group II (Gr II) it was $15.30 \pm 24.83$. The estimated Hazard Ratio (HR) (Gr I/Gr II) was 0.768 (95\% CI [0.484, 1.218]; $P=0.171)$. Patients were extubated approximately 1 hour earlier in the Gr I compared to $\mathrm{Gr}$ II which was not statistically significant. (Figure. 2)

The median time from surgery to ICU stay was 1 day shorter for patients in the Group I compared with those in the Group II (3 days, IQR [3- 4] vs. 4 days, IQR [3- 4.5].

The estimated Hazard Ratio (HR )(Gr I/Gr II) of 0.869 (95\% CI $[0.548,1.377] ; P=0.171)$, indicates that, at any given time, the "hazard" of discharge from ICU was earlier in $12 \%$ patients in Group I than in Group II.(Figure. 2)

Assessment of pain as done with resting VAS scores, found to be significantly lower in Gr I at $0 \mathrm{hr}(\mathrm{p}=0.000), 4 \mathrm{hr}(\mathrm{p}=0.000)$ and after extubation compared to Gr II. When we consider VAS scores during coughing, it was found to be significantly lower at $0 \mathrm{hr}(\mathrm{p}=0.000), 4 \mathrm{hr}$ $(\mathrm{p}=0.000), 8 \mathrm{hrs}(\mathrm{p}=0.000)$ and $12 \mathrm{hrs}(\mathrm{p}=0.010)$ in Group I than in Group II (Figure 2).
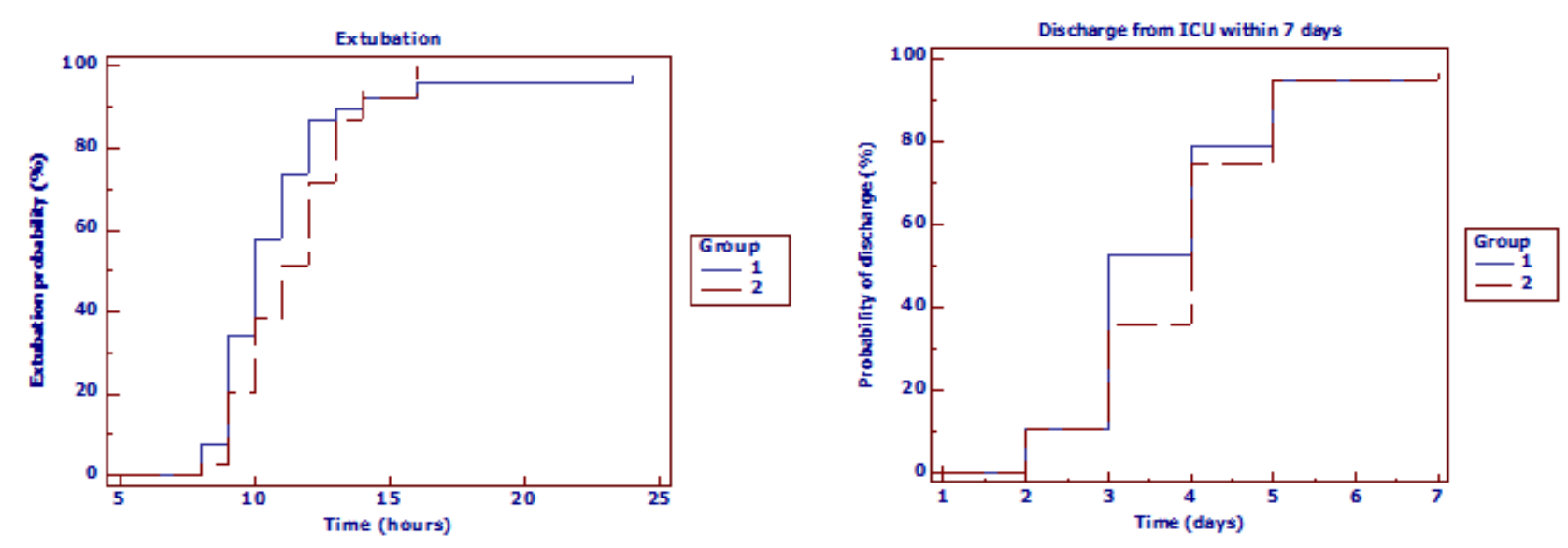

A

$\mathrm{B}$
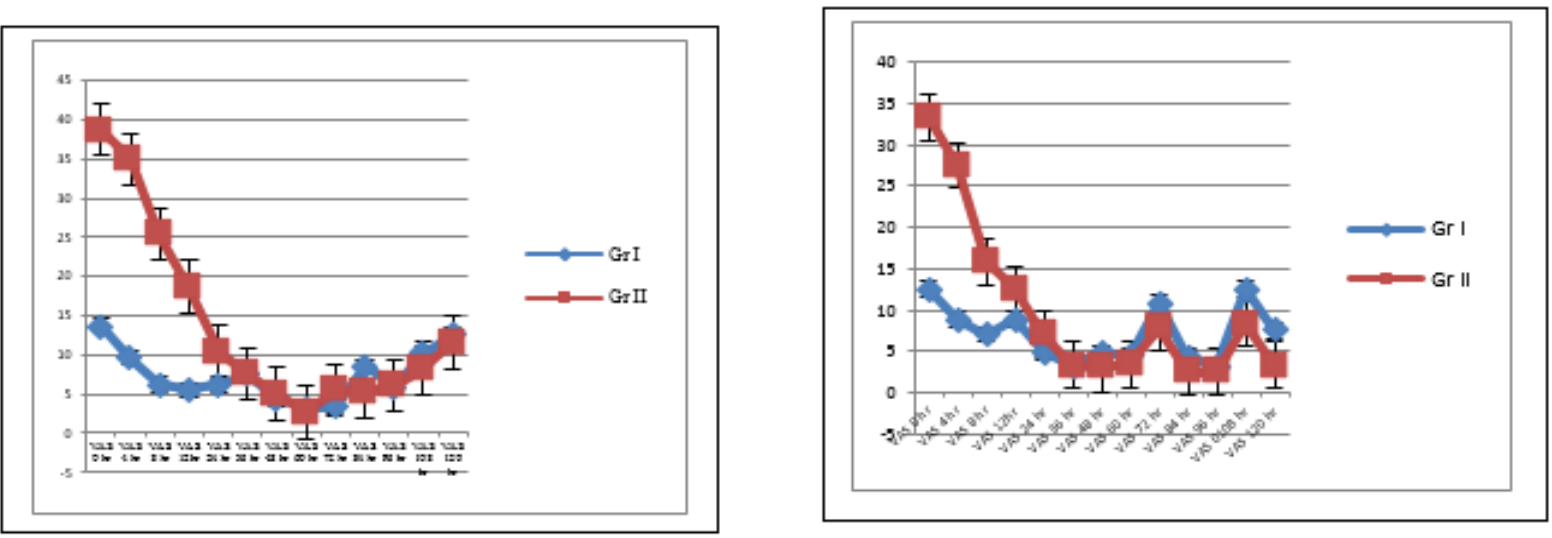

C

D

*= $\mathrm{P}<0.05$ (Mann Whitney ' $\mathrm{U}$ ' test)

Figure 2: Kaplan-Meier curves for time-to-event outcomes. (A) Time to extubation. (B) Length of intensive care unit stay (truncated at day 7) (C) Serial VAS Scores at rest. (D) Serial VAS Scores at Coughing

Patients needing rescue analgesic was found to be significantly higher in Group II compared to Group I with odds ratio 3.95, CI (1.54- 10.11) $(\mathrm{p}=$ 0.006.) Again, total requirement of tramadol was lower in Gr I $(65.21 \pm 93.46 \mathrm{mg})$ compared to Gr II $(204.0 \pm 215.01 \mathrm{mg})$ which was statistically significant $(\mathrm{p}=0.006)$. Requirement of NTG was significantly lower in Group I with $\mathrm{P}=0.005$ as depicted in Table 2. However, there was no significant difference between the groups with regard to the need for postoperative inotropes $(P=0.49)$ and vasopressors $(\mathrm{p}=0.23)$ 


\begin{tabular}{|c|c|c|c|}
\hline & $\begin{array}{l}\text { Gr I }(n=40) \\
\text { Mean } \pm \text { SD }\end{array}$ & $\begin{array}{l}\text { Gr II }(n=40) \\
\text { Mean } \pm \text { SD }\end{array}$ & $\mathbf{p}^{*}$ value \\
\hline Tramadol (mg) & $65.217 \pm 93.462$ & $204.000 \pm 215.019$ & 0.006 \\
\hline Dopamine (mg) & $341.6 \pm 201.05$ & $376.0 \pm 147.19$ & 0.49 \\
\hline NTG(mg) & $29.72 \pm 12.8$ & $42.16 \pm 16.72$ & 0.005 \\
\hline Adrenalin (mg) & $3.92 \pm 5.49$ & $3.68 \pm 4.6$ & 0.86 \\
\hline \multirow{2}{*}{ Noradrenalin (mg) } & $0.18 \pm 0.44$ & $0.4 \pm 0.76$ & 0.23 \\
\hline & $\begin{array}{l}\text { Gr I }(n=40) \\
\text { Median } \pm \text { IQR }\end{array}$ & $\begin{array}{l}\text { Gr II }(n=40) \\
\text { Median } \pm \text { IQR }\end{array}$ & p* value \\
\hline PCO2 : Preinduction & $35.60(33.55-36.50)$ & $35.81(35.50-36.50)$ & 0.237 \\
\hline $\begin{array}{l}\text { PCO2 } \\
\text { :Intraoperative(after } \\
\text { completion of all } \\
\text { anaestomosis) }\end{array}$ & $35.80(34.30-36.5)$ & $35.80(32.70-37.10)$ & 0.821 \\
\hline $\begin{array}{l}\text { PCO2 :Postoperative (1 } 1^{\text {st }} \\
\text { Day) }\end{array}$ & $35.80(33.85-36.50)$ & $37.15(35.70-39.05)$ & 0.000 \\
\hline $\begin{array}{l}\text { PCO2 :Postoperative }\left(2^{\text {nd }}\right. \\
\text { Day }\end{array}$ & $34.30(32.70-36.15)$ & $35.80(34.90-37.10)$ & 0.001 \\
\hline $\begin{array}{l}\text { PCO2 :Postoperative ( } 3^{\text {rd }} \\
\text { Day) }\end{array}$ & $35.80(34.30-36.50)$ & $35.80(35.50-36.50)$ & 0.551 \\
\hline
\end{tabular}

*p value calculated using Mann Whitney "U" test

Table 2: Total Peri-operative Requirement of Analgesic, Inotropes and Vasopressors

The incidence of lower respiratory tract infection was $17.50 \%$ in $\mathrm{Gr}$ I compared with $32.5 \%$ in the Gr II (OR 0.44; 95\%CI [0.15- 1.26])( $\mathrm{p}=0.196)$ (Table. 3)

The incidence of new arrhythmia was significantly lower in the Gr I compared with the Gr II (OR 0.21, 95\% CI [0.05-0.84], p=0.037)

(Table. 3).
Incidence of vomiting was also found to be significantly less $(\mathrm{p}=0.025)$ in Group I when compared to Group II [OR 0.16 (0.03- 0.78)] (Table. 3)

No significant difference was found between the two groups regarding postoperative incidence of Myocardial infarction (MI), Cerebrovascular accident (CVA), renal failure and postoperative need for blood transfusion.

\begin{tabular}{|l|lc|lc|c|c|}
\hline & \multicolumn{2}{|c|}{$\begin{array}{c}\text { Group I (n= 40) } \\
\mathrm{n} \%\end{array}$} & \multicolumn{2}{|c|}{$\begin{array}{c}\text { Group II (n=40) } \\
\mathrm{n} \%\end{array}$} & OR (95\%CI) & P value \\
\hline Abnormal Chest X ray & 7 & $17.50 \%$ & 10 & $25 \%$ & $0.64(0.21-1.88)$ & 0.586 \\
\hline $\begin{array}{l}\text { Incidence of Chest } \\
\text { Infection }\end{array}$ & 7 & $17.50 \%$ & 13 & $32.50 \%$ & $0.44(0.15-1.26)$ & 0.196 \\
\hline $\begin{array}{l}\text { Postoperative } \\
\text { Myocardial Infarction }\end{array}$ & 5 & $12.50 \%$ & 11 & $27.50 \%$ & $0.38(.12-1.21)$ & 0.161 \\
\hline $\begin{array}{l}\text { Cerebro-vascular } \\
\text { Accident }\end{array}$ & 1 & $2.50 \%$ & 3 & $7.50 \%$ & $0.32(0.03-3.18)$ & 0.615 \\
\hline Arrythmia & 3 & $7.50 \%$ & 11 & $27.50 \%$ & $0.21(0.05-0.84)$ & 0.037 \\
\hline Renal Failure & 4 & $10 \%$ & 6 & $15 \%$ & $0.63(0.16-2.43)$ & 0.737 \\
\hline Blood Transfusion & 16 & $40 \%$ & 11 & $27.50 \%$ & $1.76(0.69-4.50)$ & 0.344 \\
\hline Vomiting & 2 & $5 \%$ & 10 & $25 \%$ & $0.16(0.03-0.78)$ & 0.025 \\
\hline Hypotension & 10 & $25 \%$ & 2 & $5 \%$ & $6.33(1.29-31.13)$ & 0.025 \\
\hline Hypertension & 2 & $5 \%$ & 1 & $2.50 \%$ & $0.49(0.39-0.61)$ & 1.000 \\
\hline Re-exploration & 3 & $7.50 \%$ & 3 & $7.50 \%$ & $1.0(0.19-5.28)$ & 1.000 \\
\hline Re- intubation & 2 & $5 \%$ & 2 & $5 \%$ & $1.0(0.13-7.46)$ & 1.000 \\
\hline Death & 1 & $2.50 \%$ & 2 & $5 \%$ & $2.05(0.18-23.60)$ & 1.000 \\
\hline
\end{tabular}

Table 3: Secondary Outcomes and Adverse Effects $(O R=O d d s$ Ratio, $C I=$ Confidence Interval $)$

Three deaths occurred during the study: one in the Gr II and two in the Gr I. The causes of death were multifactorial (multiorgan failure, CVA, and incomplete revascularization).

\section{Discussion}

Fast tracking of CABG patients by reducing postoperative morbidity and improving overall quality of care is primary target of recent anaesthesia practice. Any technique helping to reduce the incidence of adverse outcome and earlier postoperative recovery, benefits both for patients and hospital. In this study, it was found that adding high thoracic epidural anesthesia to general anesthesia with "conventional" postoperative analgesia reduces the length of postoperative intensive care unit stay by an average of 1 day (although $\mathrm{p}>0.05$ ). Its use also reduces postoperative arrhythmias, incidence of chest infection and vomiting, decreases 
postoperative pain, increases mobility, and physiotherapy cooperation in patients undergoing $\mathrm{OPCAB}$ along with decreasing the requirement of opioid and associated adverse effects.

Kehlet [14] suggests that superior analgesia, that provided by epidural local anesthesia, should allow a more rapid recovery taking the advantage of patient's better ability to mobilize. We were unable to confirm the theory by use of TEA in CABG, as we have not found significant difference in time for extubation or length of ICU stay (although reduction of stay by an average of 1 day. Svircevic V et al [20], in a meta-analysis of more than 2,700 cardiac surgery patients in 28 studies proved, addition of thoracic epidural anesthesia significantly reduced supraventricular arrhythmias and respiratory complications, but not mortality, myocardial infarction, or stroke. They were also unable to demonstrate a benefit of fast tracking as was found in the present study.

Requirement of analgesics was significantly lower in Group I, and so also the need for nitroglycerine, which can be explained by the analgesic potency and vasodilatory effect of high thoracic epidural analgesia respectively.

There was a significant decreased incidence of new arrhythmias in the Gr I compared with Gr II (OR 0.21, 95\% CI [0.05-0.84], p 0.037). This is consistent with previous studies which also reported similar reduction in new supraventricular arrhythmias $[15,16,19,20]$. In anesthetized patients, the major determinant of heart rate is the balance between sympathetic and parasympathetic activity. High epidural analgesia blocks the cardiac afferent and efferent sympathetic fibers, resulting in a loss of the chronotropic and inotropic drive to the myocardium. This results in significant improvement in intraoperative stability, and incidence of postoperative arrhythmias.

Regarding myocardial ischemia, cardiac sympathectomy results in lower heart rates and reduced afterload, thereby reducing perioperative oxygen consumption $[17,18]$. The present study could not found decreased incidence $(8.6 \%$ vs $12 \% \mathrm{p}=1.000)$ of myocardial infarction, which occurred probably due to vasospasm, incomplete revascularization, or acute graft occlusion.

Pain scores were found to be significantly different only in the first 12 hours after surgery. In this period with a conventional large-dose opioid anesthesia, majority of patients were sedated. It suggests that fast-tracking in cardiac anesthesia could be possible using TEA with superior analgesia and better patient comfort.

The main argument against the use of high thoracic epidural anesthesia for OPCAB surgery is the fear of a risk of epidural hematoma aggravated by the need to administer heparin. The frequency has been found to be not more when compared to its use in noncardiac surgery, with the latest published risk estimate being 1:12,000. Such a risk must be balanced by important clinical advantages if the technique is to be justified. In OPCAB surgery, the need for heparinization is reduced to half the dose as that used for conventional on pump CABG, making the use of epidural anesthesia a more attractive approach. There is no evidence in the literature to suggest any increased risk or potential medical-legal concerns with epidural even with full heparinization on CPB. [1]

In this study, there was no major complications related to high thoracic epidural analgesia, and acceptance was good by both patients and paramedical staff. Though there is a risk of hypotension is significant with odds ratio 6.33 (1.29-31.13).
So, the advantages should be weighed against these potential risks of disadvantages. More studies are required to determine the clinical advantages over this potential serious risk for the technique to be justified.

The major limitation of our study was that it was not blinded. Although it is recognized that lack of masking can affect the assessment of clinical parameters, all patients were treated according to strict protocols, and data were collected by persons unaware of the nature of the study in a consistent manner.

In conclusion, it was found that pain scores, analgesic requirements, incidence perioperative arrhythmias, chest infection and vomiting were significantly lower in Group I compared to Group II, but we could not be able to find any significant difference in time for extubation and length of ICU stay, neither in incidence of postoperative MI, CVA, renal failure, blood transfusion and death.

\section{Reference:}

1. Scott NB, Turfrey DJ, Ray DA, Nzewi O, Sutcliffe NP, Lal AB, Norrie J, Nagels WJ, Ramayya GP: A prospective randomized study of the potential benefits of thoracic epidural anesthesia and analgesia in patients undergoing coronary artery bypass grafting. Anesth Analg 2001; 93:528 -535

2. Loick HM, Schmidt C, Van Aken H, Junker R, Erren M, Berendes E, Rolf N, Meissner A, Schmid C, Scheld HH, Mo"llhoff T: High thoracic epidural anesthesia, but not clonidine, attenuates the perioperative stress response via sympatholysis and reduces the release of troponin $\mathrm{T}$ in patients undergoing coronary artery bypass grafting. Anesth Analg 1999;88: 701-709

3. Nygård E, Kofoed KF, Freiberg J, Holm S, Aldershvile J, Eliasen K, Kelbaek H: Effects of high thoracic epidural analgesia on myocardial blood flow in patients with ischemic heart disease. Circulation 2005; 111:2165-2170

4. Beattie WS, Badner NH, Choi PT: Meta-analysis demonstrates statistically significant reduction in postoperative myocardial infarction with the use of thoracic epidural analgesia. Anesth Analg 2003; 97:919-920

5. Rigg JR, Jamrozik K, Myles PS, Silbert BS, Peyton PJ, Parsons RW, Collins KS; MASTER Anaesthesia Trial Study Group: Epidural anaesthesia and analgesia and outcome of major surgery: A randomized trial. Lancet 2002; 359:1276-1282

6. Lundstrøm LH, Nygård E, Hviid LB, Pedersen FM, Ravn J, Aldershvile J, Rosenberg J: The effect of thoracic epidural analgesia on the occurrence of late postoperative hypoxemia in patients undergoing elective coronary bypass surgery: A randomized controlled trial. Chest 2005; 128:1564 -1570

7. Priestley MC, Cope L, Halliwell R, Gibson P, Chard RB, Skinner M, Klineberg PL: Thoracic epidural anesthesia for cardiac surgery: The effects on tracheal intubation time and length of hospital stay. Anesth Analg 2002; 94:275- 282

8. Ho AM, Chung DC, Joynt GM: Neuraxial blockade and hematoma in cardiac surgery: Estimating the risk of a rare adverse event that has not (yet) occurred. Chest 2000; 117:551555

9. Bracco D, Hemmerling $\mathrm{T}$ : Epidural analgesia in cardiac surgery: An updated risk assessment. Heart Surg Forum 2007; 10:E334 -337

10. Myles P S, Troedel S, Boquest M, Reeves M. the pain visual analog scale: Is It linear or nonlinear? Anesth Analg 1999;89:1517-1520.

11. Miceli A, Capoun R, Fino C, Narayan P, Bryan AJ, Angelini GD, Caputo M: Effects of angiotensin-converting enzyme inhibitor therapy on clinical outcome in patients undergoing 
coronary artery bypass grafting. J Am Coll Cardiol 2009; 54:1778- 1784

12. Murphy GJ, Reeves BC, Rogers CA, Rizvi SI, Culliford L, Angelini GD: Increased mortality, postoperative morbidity, and cost after red blood cell transfusion in patients having cardiac surgery. Circulation 2007; 116:2544 -2552

13. Miceli A, Capoun R, Fino C, Narayan P, Bryan AJ, Angelini GD, Caputo M: Effects of angiotensin-converting enzyme inhibitor therapy on clinical outcome in patients undergoing coronary artery bypass grafting. J Am Coll Cardiol 2009; 54:1778-1784

14. Kehlet H. Multimodal approach to control postoperative pathophysiology and rehabilitation. Br J Anaesth 1997;78:606617.

15. Liem TH, Hasenbos MA, Booij LH, Gielen MJ. Coronary artery bypass grafting using two different anaesthetic techniques. II. Postoperative outcome. J Cardiothorac Vasc Anesth 1992;6: 156-161.
16. Gonca S, Kilickan L, Dalcik C, Dalcik H, Bayindir O: The cardioprotective effects of thoracal epidural anaesthesia are induced by the expression of vascular endothelial growth factor and inducible nitric oxide synthase in cardiopulmonary bypass surgery. J Cardiovasc Surg 2007; 48:93-102

17. Blomberg S, Emanuelsson H, Kvist H. Effects of thoracic epidural anaesthesia on coronary arteries and arterioles in patients with coronary artery disease. Anesthesiology 1990;73:840-847.

18. Stenseth R, Bjella L, Berg EM, et al. Thoracic epidural analgesia in aortocoronary bypass surgery. II. Effects on the endocrine metabolic response. Acta Anaesthesiol Scand 1994;38:834-839.

19. Royse CF: High thoracic epidural anaesthesia for cardiac surgery. Curr Opin Anaesthesiol 2009; 22:84 -87

20. Svircevic V, Nierich A, Moons K, Diephuis C, Ennema J, Brandon Bravo Bruinsma G, Kalkman C, van Dijk D: Thoracic epidural anesthesia for cardiac surgery: A randomized trial. Anesthesiology 2011; 114:262-270

* fast, convenient online submission

* rigorous peer review by experienced research in your field

* rapid publication on acceptance

* authors retain copyrights

* unique DOI for all articles

* immediate, unrestricted online access

DOI: $10.31579 / 2641-0419 / 198$

At Auctores, research is always in progress.

Learn more www.auctoresonline.org/journals/clinical-cardiology-andcardiovascular-interventions 